\title{
A 3:1 Site-Differentiated [4Fe-4S] Cluster Immobilized on a Self-Assembled Monolayer
}

\author{
Erwin P. L. van der Geer, ${ }^{\dagger}$ Coenraad R. van den Brom,,$\stackrel{,, \$}{,}$ Imad Arfaoui, $\#$, \\ Laurent Houssiau," Petra Rudolf, ${ }^{*}$, Gerard van Koten, ${ }^{\dagger}$ Robertus J. M. Klein Gebbink, ${ }^{*, \dagger}$ and \\ Bart Hessen ${ }^{\dagger,+, s}$
}

\begin{abstract}
Chemical Biology and Organic Chemistry, Faculty of Science, Universiteit Utrecht, Padualaan 8, 3584 CH Utrecht, The Netherlands, Stratingh Institute, University of Groningen, Nijenborgh 4, 9747 AG Groningen, The Netherlands, Zernike Institute for Advanced Materials, University of Groningen, Nijenborgh 4, 9747 AG Groningen, The Netherlands, and Laboratoire Interdisciplinaire de Spectroscopie Electronique, Facultés Universitaires Notre-Dame de la Paix, Rue de Bruxelles 61, 5000 Namur, Belgium
\end{abstract}

Received: June 23, 2008; Revised Manuscript Received: August 21, 2008

\begin{abstract}
A 3:1 site-differentiated [4Fe-4S] cluster is immobilized on a thiol-functionalized self-assembled monolayer $(\mathrm{SAM})$ on $\mathrm{Au}(111)$ by thiol-thiolate exchange chemistry. Fe $2 \mathrm{p}$ signals observed by X-ray photoelectron spectroscopy support the presence of [4Fe-4S] clusters at the SAM surface; further evidence comes from the detection of $n-\mathrm{Bu}_{4} \mathrm{~N}^{+}$and cluster-derived species by secondary-ion mass spectrometry. The immobilizing interaction is sufficiently strong to allow the study of [4Fe-4S] clusters at solid-liquid interfaces.
\end{abstract}

\section{Introduction}

The widespread use nature makes of cubane-type [4Fe-4S] clusters to mediate electron transfer in redox enzymes has led to detailed studies of synthetic analogues in solution. ${ }^{1-3}$ On the other hand, studies of synthetic [4Fe-4S] clusters at solid surfaces are rare. Pickett and co-workers have immobilized [4Fe$4 \mathrm{~S}$ ] clusters by trapping them in an ionic polymer matrix on an electrode, demonstrating that the electrostatic interactions with the polymer have a large effect on the cluster redox potential. ${ }^{4}$ In a later study, [4Fe-4S] clusters were immobilized by electropolymerization. Although the molecular nature of the clusters was lost, the technique elegantly created polyferredoxinlike materials. 5

Nonetheless, no strategy has yet been reported for the immobilization of [4Fe-4S] clusters onto solid surfaces in such a way that their molecular nature is preserved and each cluster is in a well-defined but readily variable environment. In an attempt to fill this void in [4Fe-4S] cluster chemistry, we report herein the first immobilization of synthetic [4Fe-4S] clusters on alkanethiol self-assembled monolayers (SAMs) ${ }^{6,7}$ on $\mathrm{Au}(111)$ surfaces.

\section{Experimental Methods}

General. All glassware was treated with basic piranha solution (volume $\mathrm{H}_{2} \mathrm{O}: \mathrm{NH}_{3}$ (aq, conc.) $\mathrm{H}_{2} \mathrm{O}_{2}$ (aq, conc.) = 5:1: 1) at $70{ }^{\circ} \mathrm{C}$ and rinsed with milli-Q grade $\mathrm{H}_{2} \mathrm{O}$ before use. Tools used for handling SAM samples were cleaned by sonication in acetone and toluene, respectively. 1-Decanethiol was purchased

* Corresponding author. E-mail: R.J.M.KleinGebbink@uu.nl. Tel: +31302531889/3120. Fax: +31-302523615. E-mail: P.Rudolf@rug.nl. Tel: +31503634736/4974. Fax: $+31-503634879$.

${ }^{\dagger}$ Universiteit Utrecht.

* Stratingh Institute, University of Groningen.

$\S$ Zernike Institute for Advanced Materials, University of Groningen.

"Facultés Universitaires Notre-Dame de la Paix.

${ }^{\perp}$ Current address: School of Chemistry, University of Birmingham, Edgbaston, Birmingham B15 2TT, United Kingdom

\# Current address: Unité Mixte de Recherche CNRS 7070 (UFR 926), Université Pierre et Marie Curie, Campus de Jussieu, Place Jussieu 4, 75252 Paris Cedex 05, France from Aldrich. All solvents were of p.a. quality. Solvents for [4Fe-4S] clusters were distilled over $\mathrm{CaH}_{2}\left(\mathrm{DMF}\right.$ and $\left.\mathrm{CH}_{2} \mathrm{Cl}_{2}\right)$ or $\mathrm{Na}$ /benzophenone (THF) and thoroughly degassed before use.

Preparation of Self-Assembled Monolayers. $6 \mathrm{mM}$ stock solutions of 1-decanethiol and 1,12-dodecanedithiol ${ }^{8}$ in EtOH were prepared directly before use and mixed and diluted to yield a solution containing $0.9 \mathrm{mM} 1$-decanethiol and $0.1 \mathrm{mM} 1,12-$ dodecanedithiol. The $\mathrm{Au}(111)$ on mica was prepared by evaporation of gold (99.99\%) onto freshly cleaved mica (2.54 $\times 5.08 \mathrm{~cm}$ ) in a home-built, fully automated thermal evaporator, until a thickness of $150 \mathrm{~nm}$ had been achieved. The gold substrates were cut into pieces of about $10 \times 5 \mathrm{~mm}$ and flameannealed for $30 \mathrm{~s}$ with an $\mathrm{H}_{2}$ flame directly before immersion into the thiol solution. After leaving the gold substrates in the solutions in the dark for $24 \mathrm{~h}$, they were carefully washed for $30 \mathrm{~s}$ in ethanol, toluene, and 2-propanol, and spin-dried.

Immobilization of [4Fe-4S] Clusters. SAM samples were placed in $0.1 \mathrm{mM}$ solutions of $\left(n-\mathrm{Bu}_{4} \mathrm{~N}\right)_{2}\left[\mathrm{Fe}_{4} \mathrm{~S}_{4}(\mathrm{TriS})(\mathrm{SEt})\right]^{9}$ (1) in DMF under an inert glovebox atmosphere. After $10 \mathrm{~min}$, the samples were carefully washed in DMF (30 s) and $\mathrm{CH}_{2} \mathrm{Cl}_{2}(30$ s) and immediately spin-dried.

X-ray Photoelectron Spectroscopy (XPS). XPS spectra were recorded on an SSX-100 spectrometer (Surface Science Instruments, United Kingdom) equipped with a hemispherical analyzer and installed in an ultrahigh vacuum chamber with an operating pressure of $2-3 \times 10^{-13}$ bar. Spectra were obtained by using monochromatic $\mathrm{Al} \mathrm{K} \alpha$ radiation $(h v=1486.6 \mathrm{eV})$ with a spot size of $600 \mathrm{~mm}$, a resolution of $1.50 \mathrm{eV}$, an analyzer step size of $0.1 \mathrm{eV}$, and a takeoff angle of $53^{\circ}$. Acquisition times were limited to a maximum of $30 \mathrm{~min}$ on any one location to minimize radiation damage; the $\mathrm{N} 1 \mathrm{~s}$ or $\mathrm{S} 2 \mathrm{p}$ level was compared at the beginning and the end of each measurement to assess whether any gross damage had occurred. The binding energy of the Au $4 \mathrm{f}_{7 / 2}$ level $(83.8 \mathrm{eV})^{10}$ was used as a reference for the SAM samples. For the drop-cast samples on Al, the $\mathrm{N}$ $1 \mathrm{~s}$ level of the $n-\mathrm{Bu}_{4} \mathrm{~N}^{+}$was used as reference and set to the average literature value of $401.9 \mathrm{eV} \cdot{ }^{11-19}$

Prior to analysis, spectra obtained at different locations on a single sample were compared and, if sufficiently similar, added 
CHART 1: Tripodal $\mathrm{TriSH}_{3}$ Ligand and 3:1 Site-Differentiated Cluster $\left(n-\mathrm{Bu}_{4} \mathrm{~N}\right)_{2}\left[\mathrm{Fe}_{4} \mathrm{~S}_{4}\right.$ (TriS)(SEt)] (1)<smiles>CCc1c(Cn2cc(S)c3ccccc32)c(CC)c(Cn2cc(S)c3ccccc32)c(CC)c1Cn1cc(S)c2ccccc21</smiles>

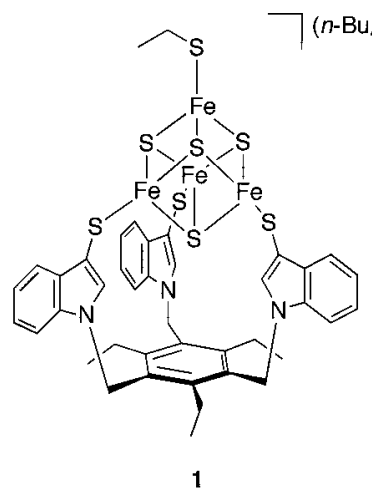

CHART 2: $\left(n-\mathrm{Bu}_{4} \mathrm{~N}\right)_{2}\left[\mathrm{Fe}_{4} \mathrm{~S}_{4}(\mathrm{SEt})_{4}\right](2)$ and

$\left(n-\mathrm{Bu}_{4} \mathrm{~N}\right)_{2}\left[\mathrm{Fe}_{4} \mathrm{~S}_{4}\left(\mathrm{~S}-3-\mathrm{C}_{8} \mathrm{H}_{5} \mathrm{~N}-1-\mathrm{C}_{10} \mathrm{H}_{21}\right)_{4}\right]$ (3)

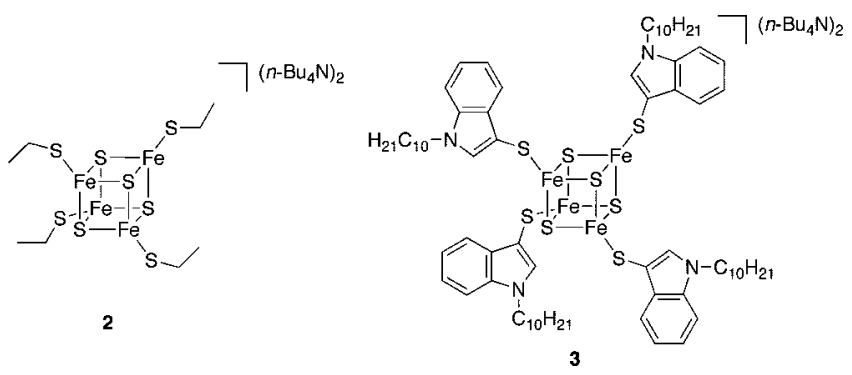

to obtain better signal-to-noise ratios. The spectra were then analyzed by mathematical reconstruction by using Winspec, a least-squares fitting program developed at the Laboratoire Interdisciplinaire de Spectroscopie Electronique, Facultés Universitaires Notre-Dame de la Paix, Namur, Belgium. Each region of interest was fitted by using a Shirley background ${ }^{20}$ and a minimal number of pure Gaussian or mixed Gaussian/Lorentzian peak functions necessary to reproduce the S, N, C, and Au regions of the spectrum. ${ }^{21}$ For the $S 2 p$ doublet, the spin-orbit coupling constant and intensity ratios were fixed at $1.18 \mathrm{eV}$ and 0.52 , respectively. If a region was fitted by using more than one signal, the Gaussian/Lorentzian mixing ratios and the peak widths were coupled. The Fe signals were fitted by using pairs of Losev singlets with coupled Losev parameters $a$ and $b .^{22}$

Elemental compositions of the samples were determined from integrated signal intensities corrected for the sensitivity factors by using data tabulated for the employed spectrometer. For the SAM samples, corrections were applied for the attenuation of buried SAM atom signals by atoms located closer to the SAM surface (see Supporting Information). The XPS characterizations of $\mathbf{1},\left(n-\mathrm{Bu}_{4} \mathrm{~N}\right)_{2}\left[\mathrm{Fe}_{4} \mathrm{~S}_{4}(\mathrm{SEt})_{4}\right]^{23}(2)$ and $\left(n-\mathrm{Bu}_{4} \mathrm{~N}\right)_{2}\left[\mathrm{Fe}_{4} \mathrm{~S}_{4}(\mathrm{~S}-3-\right.$ $\left.\left.\mathrm{C}_{8} \mathrm{H}_{5} \mathrm{~N}-1-\mathrm{C}_{10} \mathrm{H}_{21}\right)_{4}\right]^{24}$ (3) were performed on samples drop-cast from THF onto Al (99.99\%) foil under an inert glovebox atmosphere. Al was chosen rather than $\mathrm{Au}$ to prevent strong $\mathrm{Au}-\mathrm{S}$ interactions from affecting the measurement. Prior to the drop-casting, the Al foil was cleaned with soap, rinsed with milli-Q grade $\mathrm{H}_{2} \mathrm{O}$, and sonicated in acetone and toluene.

Time-of-Flight Secondary Ion Mass Spectrometry (ToFSIMS). The ToF-SIMS spectra were recorded at the Laboratoire Interdisciplinaire de Spectroscopie Electronique of the Facultés Universitaires Notre-Dame de la Paix, Namur, Belgium on a TOF-SIMS IV spectometer manufactured by IONTOF GmbH (Münster, Germany). A primary ion beam of $25 \mathrm{keV} \mathrm{Ga}^{+}$ions was applied at an incidence angle of $45^{\circ}$. The beam was pulsed at a frequency of $10 \mathrm{kHz}$ with a pulsed current of $1 \mathrm{pA}$. The mass resolution $M / \delta M$ was 7000 in both positive and negative
TABLE 1: Binding Energies (BE) of Selected Core Levels in 1 Drop-Cast on Al Foil

\begin{tabular}{|c|c|c|c|c|}
\hline & \multirow[b]{2}{*}{$\mathrm{BE}(\mathrm{eV})$} & \multirow[b]{2}{*}{ fwhm $^{a}(\mathrm{eV})$} & \multicolumn{2}{|c|}{ stoichiometry } \\
\hline & & & found & calculated \\
\hline Fe $2 p_{1 / 2}$ & 721.0 & 1.51 & & \\
\hline $\mathrm{Fe} 2 \mathrm{p}_{3 / 2}$ & 707.9 & 1.51 & 3.3 & 4 \\
\hline $\mathrm{S} 2 \mathrm{p}_{3 / 2}$ & 161.4 & 1.82 & $8^{b}$ & 8 \\
\hline N1 1s & 399.6 & 1.74 & 3.3 & 3 \\
\hline $\mathrm{N} 21 \mathrm{~s}$ & $401.9^{b}$ & 1.74 & 2.2 & 2 \\
\hline $\mathrm{C} 1 \mathrm{1s}$ & 284.4 & 1.89 & 67.8 & \\
\hline C2 1s & 285.8 & 1.89 & 19.0 & 73 \\
\hline $\mathrm{C} 31 \mathrm{~s}^{c}$ & 290.3 & 1.89 & 0.6 & \\
\hline
\end{tabular}

polarities. The analyzed area measured $100 \times 100 \mu \mathrm{m}^{2}$. The total ion fluence was typically $10^{12}$ ions $/ \mathrm{cm}^{2}$. Secondary ions were extracted with an extractor voltage of $2 \mathrm{kV}$.

\section{Results and Discussion}

Immobilization Strategy: [4Fe-4S] Cluster. In order for both the structure and the environment of immobilized clusters to remain well-defined, the immobilizing interaction should be unambiguous and strong enough to resist workup conditions. Each iron atom in a synthetic or natural [4Fe-4S] cluster is usually coordinated by a thiolate ligand, which can be exchanged for other thiolates by means of thiol-thiolate exchange chemistry. ${ }^{25,26}$ By utilizing a SAM functionalized with surface thiol groups, thiol-thiolate exchange could immobilize a dissolved [4Fe-4S] cluster onto a SAM surface by a strong coordination bond.

For the binding mode to be unambiguous, each cluster should be able to bind to the surface in one way only. This can be achieved by using a 3:1 site-differentiated cluster such as ( $n$ $\left.\mathrm{Bu}_{4} \mathrm{~N}\right)_{2}\left[\mathrm{Fe}_{4} \mathrm{~S}_{4}\right.$ (TriS)(SEt)] (1, Chart 1), the synthesis of which we have recently optimized. ${ }^{9}$ In this cluster, the $[4 \mathrm{Fe}-4 \mathrm{~S}]$ core is bound to the chelating, tripodal TriS ${ }^{3-}$ ligand (Chart 1), which blocks ligand exchanges at all but one of the iron sites. Only the unique iron atom is available for binding to the thiolfunctionalized SAM surface. ${ }^{27}$

In order to facilitate X-ray photoelectron spectroscopy (XPS) analysis of immobilized [4Fe-4S] cluster samples, we first performed XPS measurements of $\mathbf{1}$ drop-cast on $\mathrm{Al}$ foil from THF (Figure 1 and Table 1).

The data do not indicate the presence of more than one iron species in $\mathbf{1}$, despite the fact that $\mathbf{1}$ contains both $\mathrm{TriS}^{3-}$ - and ethanethiolate-coordinated iron atoms. In contrast, the broadness of the S 2p doublet suggests independent contributions from the different types of sulfur atoms in $\mathbf{1}$, although fits of the signal with more than one doublet did not converge to realistic intensity ratios. The carbon signal could be reproduced well by using three peaks, including a signal assigned to shakeup effects. The $\mathrm{N}$ 1s peaks at 401.9 and $399.6 \mathrm{eV}$ converged to an intensity ratio of 2:3.1, in excellent agreement with their assignment as the $n-\mathrm{Bu}_{4} \mathrm{~N}^{+}$and $\mathrm{TriS}^{3-}$ nitrogen atoms, respectively. In general, the stoichiometry of $\mathbf{1}$ determined from XPS is reasonable, although the intensities of the carbon and nitrogen signals are rather higher than expected.

To confirm the insensitivity of the Fe $2 p$ signals to the nature of the coordinating thiolate, we also analyzed the related, symmetrically substituted cluster $\left(n-\mathrm{Bu}_{4} \mathrm{~N}\right)_{2}\left[\mathrm{Fe}_{4} \mathrm{~S}_{4}(\mathrm{SEt})_{4}\right]^{23}(\mathbf{2}$, Chart 2) and its $N$-decylindole-3-thiolate counterpart ( $n$ $\left.\mathrm{Bu}_{4} \mathrm{~N}\right)_{2}\left[\mathrm{Fe}_{4} \mathrm{~S}_{4}\left(\mathrm{~S}-3-\mathrm{C}_{8} \mathrm{H}_{5} \mathrm{~N}-1-\mathrm{C}_{10} \mathrm{H}_{21}\right)_{4}\right]^{24}$ (3, Chart 2). The Fe $2 \mathrm{p}_{1 / 2}$ and $2 \mathrm{p}_{3 / 2}$ binding energies in $\mathbf{2}$ were determined to be 721.1 

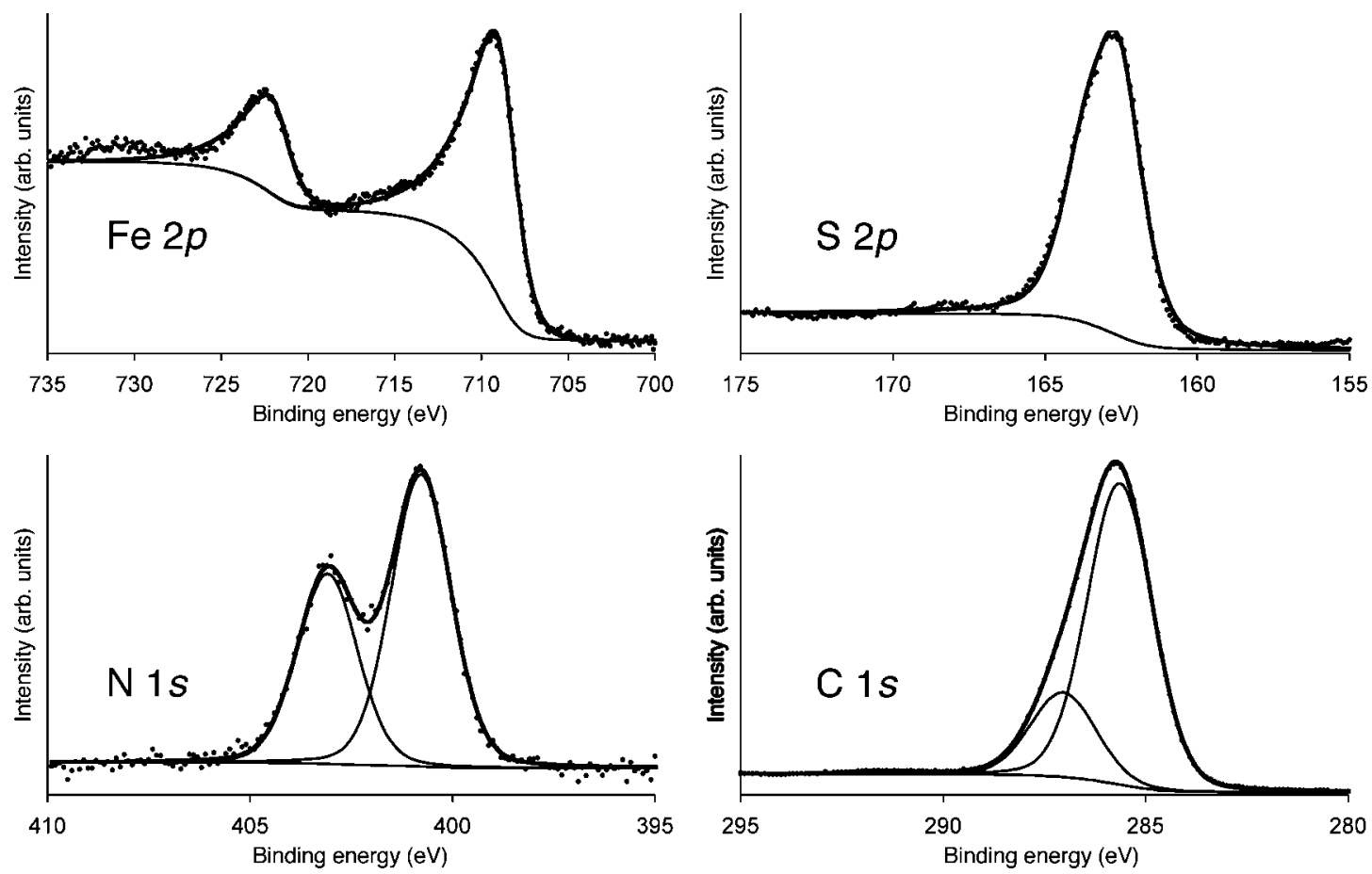

Figure 1. X-ray photoemission spectra of the Fe 2p, S 2p, N 1s, and C 1s core level regions of 1 drop-cast on Al foil.
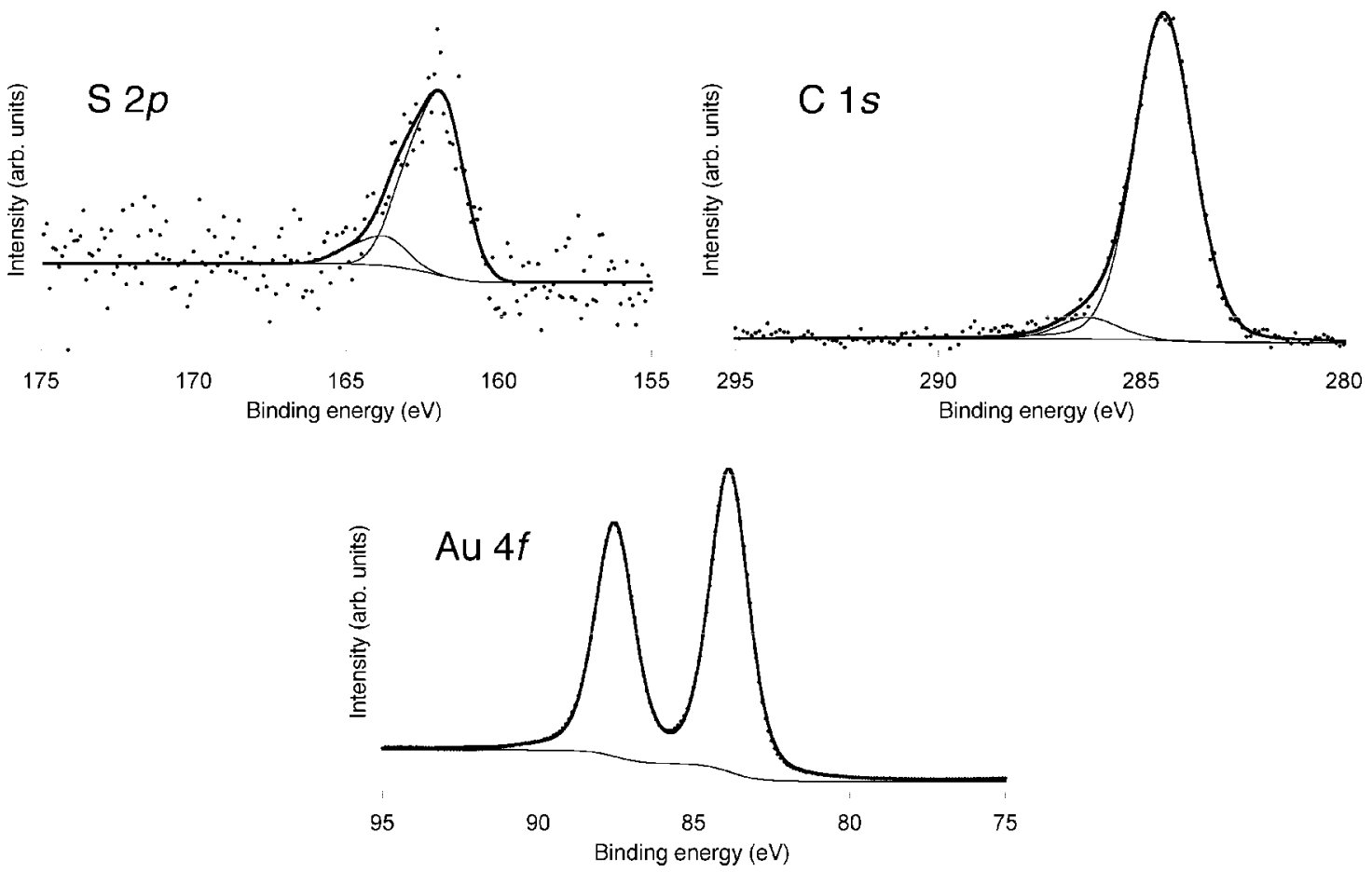

Figure 2. X-ray photoemission spectra of the S 2p, C 1s, and Au 4f core-level regions of the mixed monothiol/dithiol SAM on Au(111) on mica.

and $708.0 \mathrm{eV}$, respectively; those in $\mathbf{3}$ were 721.2 and 708.1 $\mathrm{eV}$, respectively. The negligible differences prove that the iron atoms in 1 should be indistinguishable by XPS. In all three clusters, the $\mathrm{Fe} 2 \mathrm{p}_{3 / 2}$ binding energies are relatively close to that of pyrite $\left(\mathrm{FeS}_{2}, 707.4 \mathrm{eV}\right)^{10}$ but lower than the value reported by Holm and co-workers for $\left(n-\mathrm{Pr}_{4} \mathrm{~N}\right)_{2}\left[\mathrm{Fe}_{4} \mathrm{~S}_{4}(\mathrm{SEt})_{4}\right]$ $(710.4 \mathrm{eV}) .{ }^{28}$ Most likely, a difference in the utilized reference standards is responsible for the anomaly.

Immobilization Strategy: Thiol-Functionalized SAM. In practice, the simplest conceivable SAM with surface thiol groups is one consisting of an $\alpha, \omega$-alkanedithiol on a $\mathrm{Au}(111)$ surface.
However, the dense packing of surface thiol groups in such a SAM might hinder reactions of the thiol groups with dissolved clusters. In contrast, using a mixed SAM consisting of 1-decanethiol and the slightly longer 1,12-dodecanedithiol creates a surface of protruding thiol groups with more space to react with 1 (Scheme 1).

The mixed SAMs were synthesized on $\mathrm{Au}(111)$ on mica from ethanol solutions containing the mono- and dithiols in a 9:1 ratio. At the utilized thiol concentrations, 1,12-dodecanedithiol tends to bind to a $\mathrm{Au}(111)$ surface with one thiol group only. ${ }^{29}$ Furthermore, the $2 \mathrm{D}$ crystallization of the monothiol presents a 

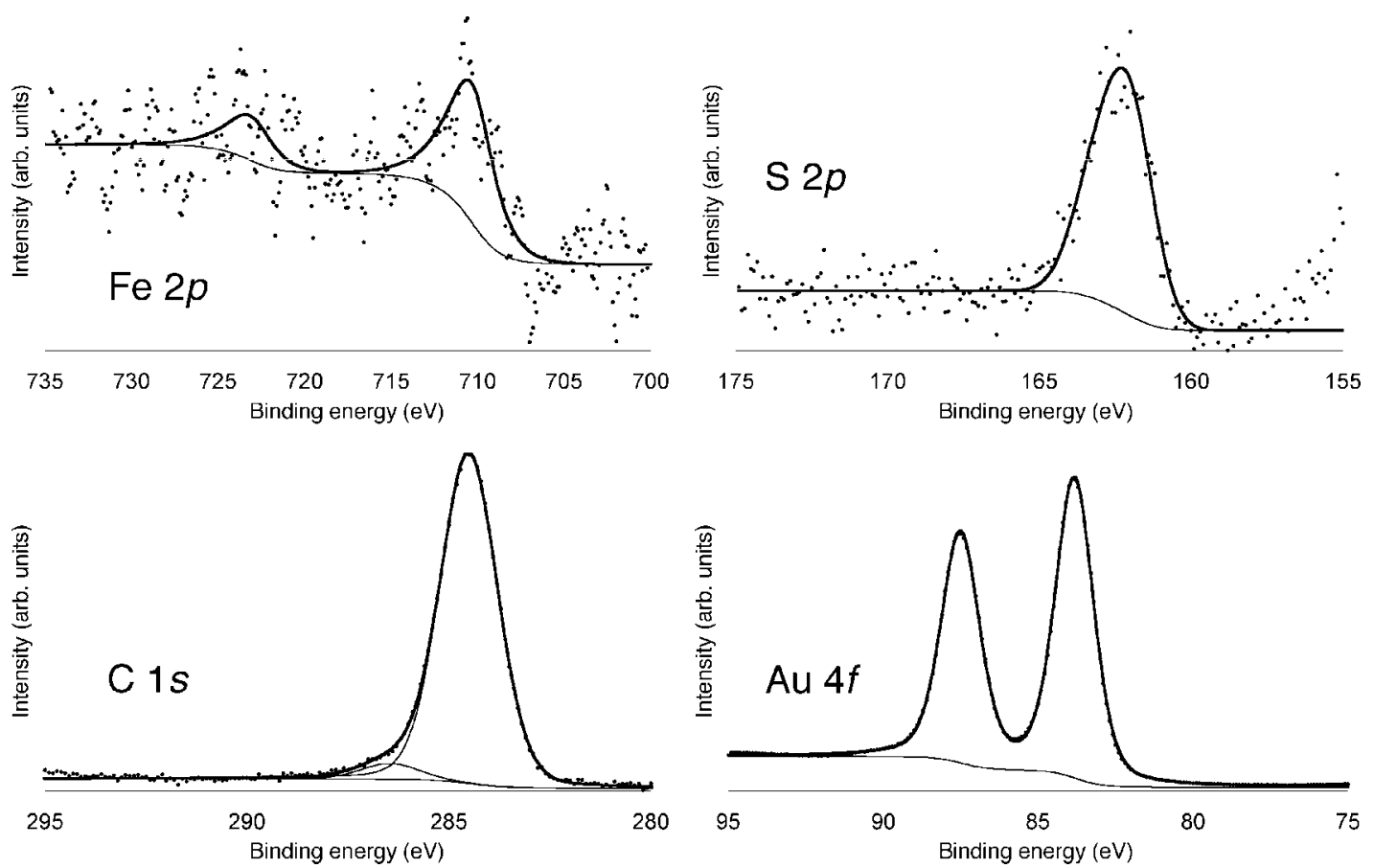

Figure 3. X-ray photoemission spectra of the Fe 2p, S 2p, C 1s, and Au $4 \mathrm{f}$ core-level regions of the mixed monothiol/dithiol SAM treated with cluster 1 . The $\mathrm{Fe} 2 \mathrm{p}$ data is given as a moving average over five points.

\section{SCHEME 1: Immobilization of 1 on a Mixed SAM with Surface Thiol Groups}

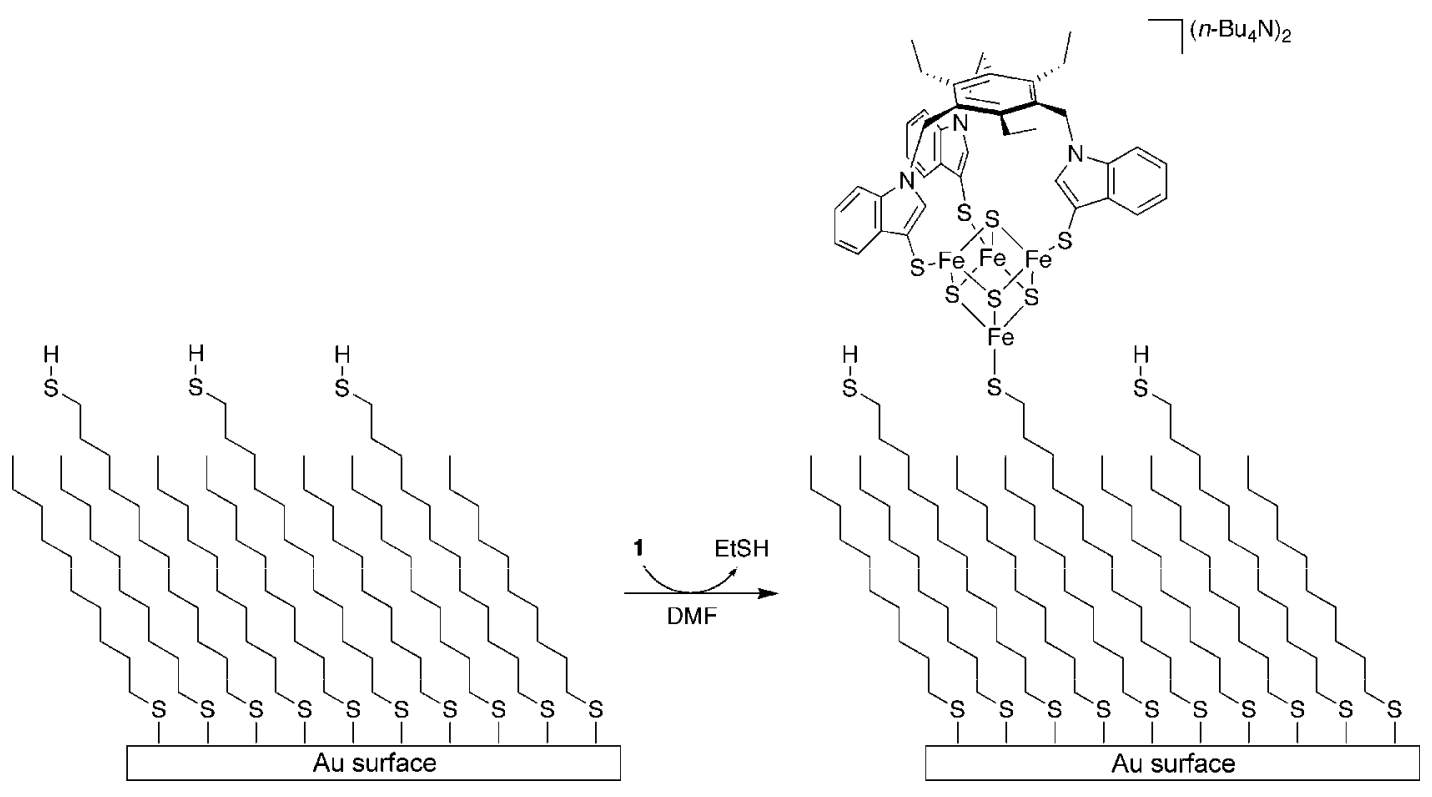

strong driving force for breaking up any bridging $\mathrm{Au}-\mathrm{S}$ interactions. XPS results for the SAM are summarized in Figure 2 and Table 2.

The S $2 p$ region contains two overlapping signals: a major doublet at $161.7 \mathrm{eV}$ corresponding to surface-bound thiol groups and a minor doublet at $163.6 \mathrm{eV}$ corresponding to unbound thiol groups at the SAM surface (and possibly also products of radiation damage). ${ }^{30-32}$ After correcting the intensity of the signal at $161.7 \mathrm{eV}$ for attenuation (see Supporting Information), the ratio between the two signals is 10.1:1. This corresponds to a monothiol:dithiol ratio of 9.1:1, in excellent agreement with the ratio of the two species in solution.

The $\mathrm{C} 1 \mathrm{~s}$ region can also be modeled as arising from two overlapping signals: one for sulfur-bound methylene carbon atoms at $286.2 \mathrm{eV}$ and one for the remaining carbon atoms at $284.4 \mathrm{eV}^{33}$ The ratio between these sulfur-bound and nonsulfur-bound carbon atoms was found to be somewhat too low. Possibly, the peak fitting underrepresented the sulfur-bound carbon signal, but the fact that the overall carbon signal intensity is also too high suggests that some carbon contamination has taken place.

Immobilization Studies. The mixed SAM was functionalized with [4Fe-4S] clusters by reaction with $\mathbf{1}$ in DMF, followed by washing in $\mathrm{CH}_{2} \mathrm{Cl}_{2}$ and spin-drying to remove unbound cluster. Subsequent XPS analysis of the mixed SAM clearly revealed $\mathrm{Fe} 2 \mathrm{p}_{1 / 2}$ and $2 \mathrm{p}_{3 / 2}$ signals at 723.1 and $710.3 \mathrm{eV}$, respectively (Figure 3 and Table 3 ). These binding energies are higher than the values found for 1 drop-cast on $\mathrm{Al}$ foil, probably because 
TABLE 2: Binding Energies (BE) of Selected Core Levels in the Mixed Monothiol/Dithiol SAM on Au(111) on Mica

\begin{tabular}{lcccc}
\hline & & & \multicolumn{2}{c}{ stoichiometry } \\
\cline { 4 - 5 } & $\mathrm{BE}(\mathrm{eV})$ & fwhm $(\mathrm{eV})$ & found & calculated \\
\hline $\mathrm{S} 1 \mathrm{p}_{3 / 2}$ & 161.7 & 1.59 & 10.1 & 10 \\
$\mathrm{~S} 2 \mathrm{p}_{3 / 2}$ & 163.6 & 1.59 & $1^{a}$ & 1 \\
$\mathrm{C} 1 \mathrm{~s}$ & 284.4 & 1.71 & 101.3 & 91 \\
$\mathrm{C} 21 \mathrm{~s}$ & 286.2 & 1.71 & 8.1 & 11 \\
$\mathrm{Au} 4 \mathrm{f}$ & $83.8^{a, b}$ & 1.48 & & \\
${ }^{a}$ Used as reference values & ${ }^{b}$ Splitting $=3.67 \mathrm{eV}$.
\end{tabular}

TABLE 3: Binding Energies (BE) of Selected Core Levels in the Mixed Monothiol/Dithiol SAM Treated with 1

\begin{tabular}{lccccc}
\hline & & & \multicolumn{3}{c}{ stoichiometry } \\
\cline { 5 - 6 } & $\mathrm{BE}(\mathrm{eV})$ & fwhm $^{a}(\mathrm{eV})$ & found & found $^{b}$ & calculated $^{b}$ \\
\hline $\mathrm{Fe} \mathrm{2} 2 \mathrm{p}_{1 / 2}$ & 723.1 & 1.02 & & & \\
$\mathrm{Fe} \mathrm{2} \mathrm{p}_{3 / 2}$ & 710.3 & 1.02 & $1^{c}$ & & \\
$\mathrm{~S} \mathrm{2p}$ & 162.0 & 1.81 & 34.3 & 11 & 11 \\
$\mathrm{C} 11 \mathrm{~s}$ & 284.5 & 1.67 & & & \\
$\mathrm{C} 21 \mathrm{~s}$ & 286.4 & 1.67 & 578.5 & 189.0 & 102 \\
$\mathrm{Au} \mathrm{4f}$ & $83.8^{\text {c,d }}$ & 1.46 & & &
\end{tabular}

${ }^{a}$ Or Losev parameter $a$ for Fe 2 p. ${ }^{22}{ }^{b} \mathrm{SAM}$ only. ${ }^{c}$ Used as reference values. ${ }^{d}$ Splitting $=3.67 \mathrm{eV}$.

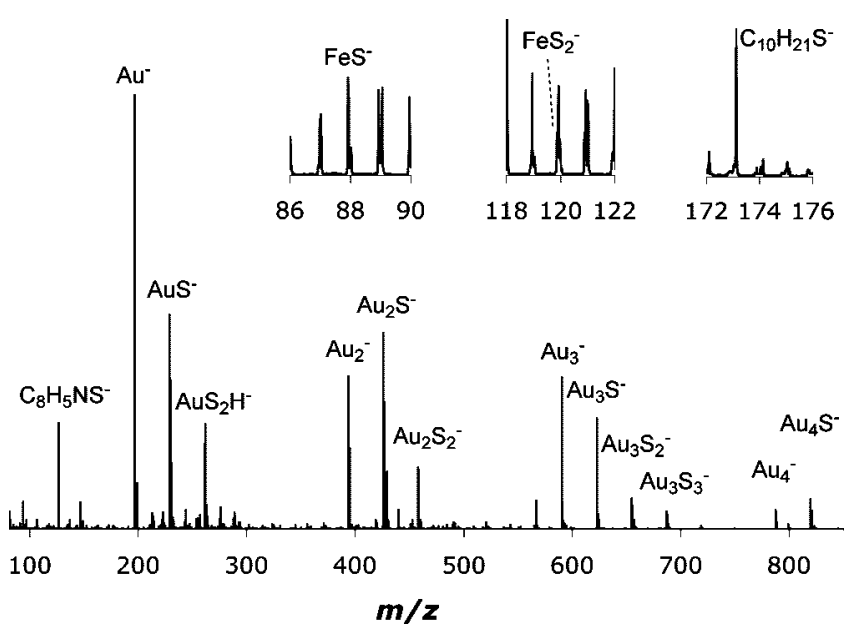

Figure 4. Negative time-of-flight secondary-ion mass spectrum of the mixed monothiol/dithiol SAM treated with cluster 1. Insets: clusterand SAM-derived signals at 40x magnification.

the $\mathrm{N}$ 1s signal was too weak to be analyzed and could not be used as reference. Consequently, the Fe $2 \mathrm{p}_{3 / 2}$ binding energy is now close to that reported by Holm and co-workers for $\left(n-\mathrm{Pr}_{4} \mathrm{~N}\right)_{2}\left[\mathrm{Fe}_{4} \mathrm{~S}_{4}(\mathrm{SEt})_{4}\right]$ (vide supra). ${ }^{28}$

As in the XPS analysis of $\mathbf{1}$, the sulfur signal could only be fitted realistically with a single doublet. After correcting for contributions from immobilized clusters, the carbon and sulfur signals were corrected for attenuation disregarding any potential attenuation by cluster species. The ratio of clusters to surface thiol groups was then approximately 1:3, indicating that one in three surface thiol groups were functionalized with [4Fe-4S] clusters. The high carbon-to-sulfur ratio is again suggestive of carbon contamination.

Time-of-flight secondary-ion mass spectrometry (ToFSIMS $)^{34}$ provided further support for [4Fe-4S] cluster immobilization. As expected, ${ }^{35-37} \mathrm{Au}_{m} \mathrm{~S}_{n} \mathrm{H}_{p}{ }^{-}$species dominate the negative-ion spectrum (Figure 4). A deprotonated SAM molecular ion $\mathrm{C}_{10} \mathrm{H}_{21} \mathrm{~S}^{-}$signal is observed at $\mathrm{m} / \mathrm{z}=173.13$

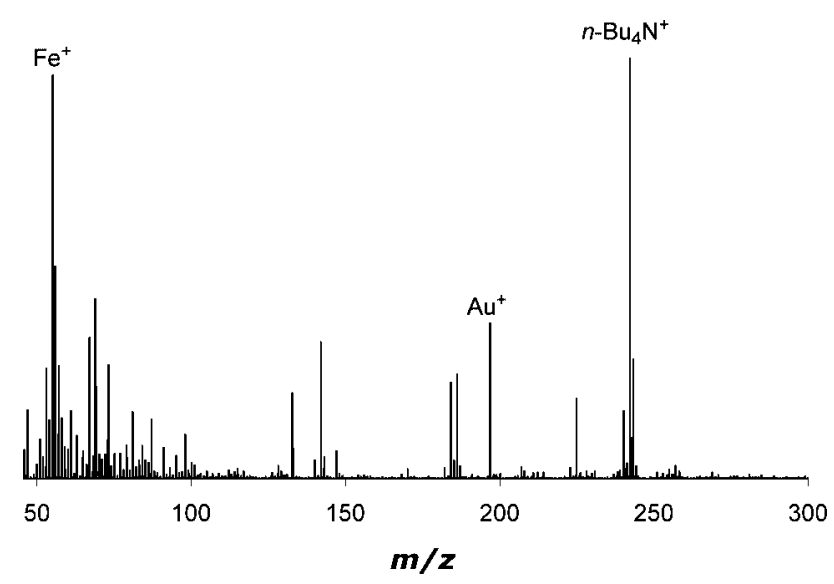

Figure 5. Positive time-of-flight secondary-ion mass spectrum of the mixed monothiol/dithiol SAM treated with cluster $\mathbf{1}$.

(calculated $\mathrm{m} / \mathrm{z}=173.13$ ). Signals at $\mathrm{m} / \mathrm{z}=87.93$ and 119.89 indicate the presence of $\mathrm{FeS}^{-}$(calculated $\mathrm{m} / \mathrm{z}=87.91$ ) and $\mathrm{FeS}_{2}{ }^{-}$(calculated $m / z=119.88$ ), respectively. Furthermore, a signal at $m / z=147.01$ can be assigned to the indolyl species $\mathrm{C}_{8} \mathrm{H}_{5} \mathrm{NS}^{-}$(calculated $\mathrm{m} / \mathrm{z}=147.01$ ), a fragmentation product of the TriS ${ }^{3-}$ ligand.

The XPS N 1s signal had been too weak to allow for analysis and assignment as the nitrogen atom in $n-\mathrm{Bu}_{4} \mathrm{~N}^{+}$. On the other hand, positive-ion ToF-SIMS (Figure 5) shows a strong signal at $m / z=242.30$ corresponding to $n-\mathrm{Bu}_{4} \mathrm{~N}^{+}$(calculated $m / z=$ 242.28). Furthermore, a clear $\mathrm{Fe}^{+}$signal is observed at $\mathrm{m} / \mathrm{z}=$ 55.94 (calculated $m / z=55.93$ ).

\section{Conclusion}

The Fe 2p XPS signals from the [4Fe-4S] cluster-treated SAM samples, together with the observation of cluster and ligand fragments and the $n-\mathrm{Bu}_{4} \mathrm{~N}^{+}$counterion in ToF-SIMS, provide strong evidence that cluster $\mathbf{1}$ has been immobilized on the mixed SAM samples. Although the exact binding mode of the cluster to the surface has not yet been elucidated, the interaction with the surface is strong enough to resist washing. Hence, the immobilization strategy enables future investigations into the behavior of the $[4 \mathrm{Fe}-4 \mathrm{~S}]$ clusters at solid-liquid interfaces.

Acknowledgment. This work was financially supported by the National Research School Combination-Catalysis (NRSCC). We thank Dr. M. Lubomska of the Zernike Institute for Advanced Materials at the University of Groningen for supplying the samples of $\mathrm{Au}(111)$ on mica and Dr. B. de Boer of the Materials Science Centre ${ }^{\text {Plus }}$ at the University of Groningen for supplying 1,12-dodecanedithiol and access to cleanroom facilities.

Supporting Information Available: Procedure for estimating XPS attenuation correction in a mixed monothiol/dithiol SAM. This material is available free of charge via the Internet at http://pubs.acs.org.

\section{References and Notes}

(1) Beinert, H.; Holm, R. H.; Münck, E. Science 1997, 277, 653-659.

(2) Johnson, M. K. Curr. Opin. Chem. Biol. 1998, 2, 173-181.

(3) Venkateswara Rao, P.; Holm, R. H. Chem. Rev. 2004, 104, 527559 .

(4) Moutet, J.-C.; Pickett, C. J. J. Chem. Soc., Chem. Commun. 1989 , 188-190.

(5) Pickett, C. J.; Ibrahim, S. K.; Hughes, D. L. Faraday Discuss. 2000, 116, 235-244. 
(6) Love, J. C.; Estroff, L. A.; Kriebel, J. K.; Nuzzo, R. G.; Whitesides, G. M. Chem. Rev. 2005, 105, 1103-1169.

(7) Chen, D.; Li, J. Surf. Sci. Rep. 2006, 61, 445-463.

(8) Akkerman, H. B.; Blom, P. W. M.; de Leeuw, D. M.; de Boer, B. Nature 2006, 441, 69-72.

(9) van der Geer, E. P. L.; van Koten, G.; Klein Gebbink, R. J. M.; Hessen, B. Inorg. Chem. 2008, 47, 2849-2857.

(10) Wagner, C. D.; Riggs, W. M.; Davis, L. E.; Moulder, J. F. Handbook of X-ray Photoelectron Spectroscopy; Muilenberg, G. E., Ed.; Perkin-Elmer Corporation: Eden Prairie, USA, 1979.

(11) Gniewek, A.; Trzeciak, A. M.; Ziólkowski, J. J.; Kêpiñski, L.; Wrzyszcz, J.; Tylus, W. J. Catal. 2005, 229, 332-343.

(12) Yang, P.; Cao, Y.; Hu, J.-C.; Dai, W.-L.; Fan, K.-N. Appl. Catal., A 2003, 241, 363-373.

(13) Liu, S.-G.; Liu, Y.-Q.; Zhu, D.-B. Synth. Met. 1997, 89, 187-191.

(14) Wenkin, M.; Devillers, M.; Tinant, B.; Declercq, J.-P. Inorg. Chim. Acta 1997, 258, 113-118.

(15) Liu, S.-G.; Liu, Y.-Q.; Liu, S.-H.; Zhu, D.-B. Synth. Met. 1995, 74, 137-143.

(16) Anderson, J. E.; Gregory, T. P.; Net, G.; Bayón, J. C. J. Chem. Soc., Dalton Trans. 1992, 487-495.

(17) Bayón, J. C.; Net, G.; Esteban, P.; Rasmussen, P. G.; Bergstrom, D. F. Inorg. Chem. 1991, 30, 4771-4777.

(18) Sieklucka, B.; Dziembaj, R.; Witkowski, S. Inorg. Chim. Acta 1991, 187, 5-8.

(19) Mialki, W. S.; Stiefel, E. I.; Bruce, A. E.; Walton, R. A. Inorg. Chem. 1981, 20, 1614-1616.

(20) Shirley, D. A. Phys. Rev. B 1972, 5, 4709-4714.

(21) Practical Surface Analysis by Auger and X-Ray Photoelectron Spectroscopy; Briggs, D., Seah, M. P., Eds.; John Wiley \& Sons: Chichester, 1983.

(22) Losev, A. Surf. Interface Anal. 1989, 14, 845-849.
(23) Christou, G. C.; Garner, C. D. J. Chem. Soc., Dalton Trans. 1979, 1093-1094.

(24) van der Geer, E. P. L.; Li, Q.; van Koten, G.; Klein Gebbink, R. J. M.; Hessen, B. Inorg. Chim. Acta 2008, 361, 1811-1818.

(25) Bobrik, M. A.; Que, L., Jr.; Holm, R. H. J. Am. Chem. Soc. 1974, 96, 285-287.

(26) Que, L., Jr.; Bobrik, M. A.; Ibers, J. A.; Holm, R. H. J. Am. Chem. Soc. 1974, 96, 4168-4178.

(27) Walsdorff, C.; Saak, W.; Pohl, S. J. Chem. Soc., Dalton Trans. 1997, 1857-1861.

(28) Holm, R. H.; Averill, B. A.; Herskovitz, T.; Frankel, R. B.; Gray, H. B.; Siiman, O.; Grunthaner, F. J. J. Am. Chem. Soc. 1974, 96, 26442646.

(29) Akkerman, H. B.; Kronemeijer, A. J.; van Hal, P. A.; de Leeuw, D. M.; Blom, P. W. M.; de Boer, B. Small 2008, 4, 100-104.

(30) Laibinis, P. E.; Whitesides, G. M.; Allara, D. L.; Tao, Y.-T.; Parikh, A. N.; Nuzzo, R. G. J. Am. Chem. Soc. 1991, 113, 7152-7167.

(31) Castner, D. G.; Hinds, K.; Grainger, D. W. Langmuir 1996, 12, $5083-5086$.

(32) Ishida, T.; Choi, N. Langmuir 1999, 15, 6799-6806.

(33) Mendoza, S. M.; Arfaoui, I.; Zanarini, S.; Paolucci, F.; Rudolf, P. Langmuir 2007, 23, 582-588.

(34) Van Vaeck, L.; Adriaens, A.; Gijbels, R. Mass Spectrom. Rev. 1999, $18,1-47$.

(35) Graham, D. J.; Price, D. D.; Ratner, B. D. Langmuir 2002, 18, $1518-1527$.

(36) Gillen, G.; Bennett, J.; Tarlov, M. J.; Burgess, D. R. F., Jr Anal. Chem. 1994, 66, 2170-2174.

(37) Tarlov, M. J.; Newman, J. G. Langmuir 1992, 8, 1398-1405.

JP805532M 